\title{
Modified Ammonia Removal Model Based on Equilibrium and Mass Transfer Principles
}

\author{
A. Shanableh* and M. Imteaz,** \\ Department of Civil and Environmental Engineering, University of Sharjah, Sharjah, United Arab Emirates \\ *E-mail: shanableh@sharjah.ac.ae \\ ${ }^{\dagger}$ Faculty of Engineering and Industrial Science, Swinburne University of Technology P. O. Box 218, \\ Hawthorn, Victoria, 3122, Australia. E-mail: mimteaz@swin.edu.au \\ Received December 11, 2009, Accepted May 10, 2010
}

\begin{abstract}
Yoon et al. ${ }^{1}$ presented an approximate mathmatical model to describe ammonia removal from an experimental batch reactor system with gaseous headspace. The development of the model was initially based on assuming instantaneous equilibrium between ammonia in the aqueous and gas phases. In the model, a "saturation factor, $\beta$ " was defined as a constant and used to check whether the equilibrium assumption was appropriate. The authors used the trends established by the estimated $\beta$ values to conclude that the equilibrium assumption was not valid. The authors presented valuable experimental results obtained using a carefully designed system and the model used to analyze the results accounted for the following effects: speciation of ammonia between $\mathrm{NH}_{3}$ and $\mathrm{NH}_{4}^{+}$as a function of $\mathrm{pH}$; temperature dependence of the reactions constants; and air flow rate. In this article, an alternative model based on the exact solution of the governing mass-balance differential equations was developed and used to describe ammonia removal without relying on the use of the saturation factor. The modified model was also extended to mathematically describe the $\mathrm{pH}$ dependence of the ammonia removal rate, in addition to accounting for the speciation of ammonia, temperature dependence of reactions constants, and air flow rate. The modified model was used to extend the analysis of the original experimental data presented by Yoon et al. ${ }^{1}$ and the results matched the theory in an excellent manner.
\end{abstract}

Key Words: Ammonia removal, Mathematical models, Mass transfer rate, $\mathrm{pH}$ effect

\section{Introduction}

Yoon et al. ${ }^{1}$ presented a simple mass-balance model describing ammonia removal from a small batch reactor system with headspace and outlet for the gas phase consisting of a long tube with small diameter. In the system, ammonia was removed from solution using air bubbled into the liquid in addition to headspace aeration. The experiments involved assessing the effects of temperature, $\mathrm{pH}$, and aeration on ammonia removal. The analysis of the results involved developing a mathematical model to describe system performance. The development of the model was initially based on the following three assumptions: 1. "Ammonia concentration in the aqueous phase is uniform. 2. Ammonia concentration in the air phase is uniform. 3. Ammonia concentration in the air phase is in equilibrium with the aqueous phase. In other words, ammonia in the aqueous and air phases reaches equilibrium instantly".

Yoon et al. ${ }^{1}$ used the three above assumptions to develop a mass-balance model to describe the performance of the system. Upon analyzing the experimental results, the authors ${ }^{1}$ concluded that the third assumption was not satisfied as ammonia in the air phase did not reach instantaneous equilibrium with the aqueous phase. Based on their findings, the authors ${ }^{1}$ contradicted what was stated to be the accepted hypothesis of instantaneous ammonia equilibrium $^{2,3}$ between the air bubbles and the aqueous phase during aeration. To correct for the discrepancy created by using the instantaneous equilibrium assumption, the authors ${ }^{1}$ defined a "saturation factor, $\beta$ ", which represented the ratio between the equilibrium (or saturation) concentration of ammonia
$\left(C_{L S}\right)$, as defined by Henry's law, and the measured concentration of ammonia in solution $\left(C_{L}\right)$. Furthermore, the authors ${ }^{1}$ translated the equilibrium assumption to be between ammonia in the headspace (rather than the bubbles) and the liquid. In effect, instantaneous equilibrium of ammonia in the liquid and headspace assumes that $C_{L}=C_{L S}$, which simply means that mass transfer ceases. As such, the authors used the $\beta$ as correction factor (i.e., $C_{L S}=\beta C_{L}$ ). Noting that $C_{L S}$ can be estimated from Henry's equation, then $\beta$ can be described as follows:

$$
\beta=\frac{C_{L S}}{C_{L}}=\frac{C_{g}}{\alpha_{N H_{3}} H C_{L}}
$$

where, $\beta=$ the "saturation factor", $C_{L}=$ the total concentration of ammonia (i.e., $\mathrm{NH}_{3}+\mathrm{NH}_{4}^{+}$), $\mathrm{C}_{L S}=$ the equilibrium total concentration of ammonia as defined by Henry's law (i.e., $\left.C_{L S}=\frac{C_{g}}{\alpha_{\mathrm{NH}_{3}} H}\right), C_{g}=$ the concentration of ammonia in the gaseous headspace, $H=$ Henrys constant for ammonia, and $\alpha_{\mathrm{NH}_{3}}=$ ratio of the concentration of $\mathrm{NH}_{3}$ to the total concentration of ammonia.

Although the use of the saturation factor $(\beta)$ as a constant ${ }^{1}$ may be justified as an approximation, $\beta$ in fact is a time-dependent variable. For example, at time $t=0$, the theoretical concentration of ammonia in the gaseous headspace of the reactor should be $C_{g}=0$, while the total ammonia concentration in the liquid phase $\left(C_{L}\right)$ should be at its maximum initial value of $C_{L o}$. As such, and according to Equation 1, at $t=0$, equilibrium does 


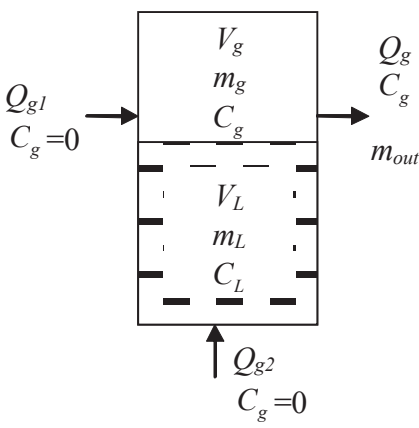

Figure 1. Simplified schematic of the experimental system used by Yoon et al. (2008). $m_{L}=$ mass of ammonia in the liquid phase; $m_{g}=$ mass of ammonia in the gaseous phase; $m_{\text {out }}=$ mass of ammonia released to the atmosphere through the outlet; $V_{L}=$ liquid volume; $V_{g}=$ gaseous headspace volume; $C_{L}$ is the total concentration of ammonia in the liquid; $C_{g}=$ concentration of ammonia in the gaseous headspace; $Q_{g 1}=$ headspace aeration rate; $Q_{g 2}=$ flow rate of air bubbled in the liquid; and $Q_{g}=$ total air flow rate (i.e., $Q_{g}=Q_{g 1}+Q_{g 2}$ ).

not exist and $\beta=0$. Theoretically, $C_{g}$ in the gaseous headspace increases with time initially, and depending on the system characteristics, may reach a maximum value then decline. On the other hand, $C_{L}$ continues to decline as ammonia removal progresses with time.

An alternative approach to using $\beta$ as a constant, an exact mathematical model can be developed based on considering $\beta$ a time-dependent variable. In this article, two solutions, exact and simplified, to the mass balance differential equation that governs system performance are formulated without the use of the saturation factor. However, both solutions can be used to determine the variations of the "saturation factor, $\beta$ " with time.

The following is a presentation of the mathematical model developed and presented by Yoon et al. ${ }^{1}$, which was based on using $\beta$ as a constant. A mass balance on ammonia removal in the batch reactor, which is depicted in Figure 1, was written as follows:

$$
m_{T}=m_{L}+m_{g}+m_{\text {out }}
$$

where, $m_{T}=$ initial total ammonia mass in the system; $m_{L}=$ mass of ammonia in the liquid phase; $m_{g}=$ mass of ammonia in the gaseous phase; and $m_{\text {out }}=$ mass of ammonia released to the atmosphere through the outlet.

Assuming that $C_{L}=C_{L S}$ or $m_{L}=m_{L S}$ (which is obviously incorrect), then $m_{L}$ in Equation 2 can be described in terms of $\mathrm{m}_{\mathrm{g}}$ using Henry's law (Equation 3), and Equation 2 can then be rearranged to yield Equation 4.

$$
\begin{gathered}
C_{L}=\frac{C_{g}}{\alpha_{N H_{3}} H}=\frac{m_{L}}{V_{L}}=\frac{m_{g}}{V_{g} \alpha_{N H_{3}} H} \\
m_{g}=\left(\frac{\alpha_{\mathrm{NH}_{3}} H V_{g}}{V_{L}+\alpha_{\mathrm{NH}_{3}} H V_{g}}\right)\left(m_{T}-m_{\text {out }}\right)
\end{gathered}
$$

where, $V_{L}=$ liquid volume; and $V_{g}=$ gaseous headspace volume.
The rate at which $m_{\text {out }}$ is released is described in Equation 5. Substituting for $m_{g}$ in Equation 5 from Equation 4 results in Equation 6. Integration of Equation 6 yields Equation 7. Equation 7 can also be expressed in terms of $m_{g}$ and $m_{L}$ as in Equations 8 and 9.

$$
\frac{d m_{\text {out }}}{d t}=Q_{g} C_{g}=Q_{g} \frac{m_{g}}{V_{g}}
$$

where $Q_{g}=$ the total gas flow rate.

$$
\begin{aligned}
& \frac{d m_{\text {out }}}{d t}=\left(\frac{Q_{g} \alpha_{N H_{3}} H}{V_{L}+\alpha_{N H_{3}} H V_{g}}\right)\left(m_{T}-m_{\text {out }}\right) \\
& m_{\text {out }}=m_{T}-m_{T}\left(\exp \left[\left(\frac{Q_{g} \alpha_{N H_{3}} H t}{V_{L}+\alpha_{N H_{3}} H V_{g}}\right)\right]\right)^{-1} \\
& m_{g}=m_{T}\left(\frac{\alpha_{N H_{3}} H V_{g}}{V_{L}+\alpha_{N H_{3}} H V_{g}}\right)\left(\exp \left[\left(\frac{Q_{g} \alpha_{N H_{3}} H t}{V_{L}+\alpha_{N H_{3}} H V_{g}}\right)\right]\right)^{-1} \\
& m_{L}=m_{T}\left(\frac{V_{L}}{V_{L}+\alpha_{N H_{3}} H V_{g}}\right)\left(\exp \left[\left(\frac{Q_{g} \alpha_{N H_{3}} H t}{V_{L}+\alpha_{N H_{3}} H V_{g}}\right)\right]\right)^{-1}
\end{aligned}
$$

To correct for the instantaneous equilibrium assumption (i.e., that $C_{L}=C_{L S}$ or $m_{L}=m_{L S}$ ) used to develop Equations 7,8 and 9 , Yoon et al. ${ }^{1}$ used the saturation factor through substituting $\beta H$ for $H$ in equation 9 to yield Equation 10:

$$
m_{L}=m_{T}\left(\frac{V_{L}}{V_{L}+\alpha_{N H_{3}} \beta H V_{g}}\right)\left(\exp \left[\left(\frac{Q_{g} \alpha_{N H_{3}} \beta H t}{V_{L}+\alpha_{N H_{3}} \beta H V_{g}}\right)\right]\right)^{-1}
$$

The direct substitution of $\beta H$ for $H$ in Equation 9 is possible only if $\beta$ is a constant that is independent of time. Otherwise, the integration of Equation 6 would not have been straight foreword as described. In fact, $\beta$ changes with time and should not be considered a time-independent constant.

\section{Modified Ammonia Removal Model}

The modified ammonia removal model is based on the use of traditional mass balance analysis of gas transfer in a batch reactor system. In developing the model, the first two of the three assumptions made by Yoon et al. ${ }^{1}$ were adopted, which are: 1 . Ammonia concentration in the aqueous phase is uniform. 2. Ammonia concentration in the gaseous phase (i.e., headspace) is uniform.

Noting that ammonia accumulates in the gaseous headspace and that the concentration of ammonia in the headspace $\left(C_{g}\right)$ changes with time, the ammonia mass balance equation on the liquid phase can be written as follows: 


$$
V_{L} \frac{d C_{L}}{d t}=-V_{L} K_{L} a\left(C_{L}-C_{L S}\right)
$$

where $K_{L} a=$ the mass transfer coefficient.

In Equation 11, the equilibrium concentration $\left(C_{L S}\right)$ varies with time influenced by the variations of $C_{g}$ in the headspace. As such, integrating Equation 11 to obtain the concentration function $C_{L}$ requires describing $C_{L S}$ as a function of time. Similarly, a mass balance on ammonia in the gaseous phase in the headspace of the reactor results in Equation 12:

$$
V_{g} \frac{d C_{g}}{d t}=V_{L} K_{L} a\left(C_{L}-C_{L S}\right)-Q_{g} C_{g}
$$

In Equations 11 and 12, $C_{L S}$ can be described in terms of $C_{g}$ using Henry's equation, as follows:

$$
C_{L S}=\frac{C_{g}}{\alpha_{N H_{3}} H}
$$

The functions describing the variations of $C_{L}$ and $C_{g}$ with time can be obtained by solving Equations 11 and 12. In this article, the following two solutions for Equations 11 and 12 are presented: (a) an exact solution; and (b) an approximate solution. In the exact solution, Equations 11 and 12 are solved as two simultaneous linear differential equations of the form described in Equations 14 and 15:

$$
\begin{aligned}
& \frac{d C_{L}}{d t}=a_{11} C_{L}+a_{12} C_{g} \\
& \frac{d C_{g}}{d t}=a_{21} C_{L}+a_{22} C_{g}
\end{aligned}
$$

The solution of the above equations takes the following forms:

$$
\begin{aligned}
& C_{L}=A e^{r_{1} t}+B e^{r_{2} t} \\
& C_{g}=\frac{r_{1}-a_{11}}{a_{12}} A e^{r_{1} t}+\frac{r_{2}-a_{11}}{a_{12}} B e^{r_{2} t}
\end{aligned}
$$

The various parameters in Equations 14 to 17 are defined in Table 1. The different values of the constants A and B were estimated using the known boundary conditions being at $t=0$, $C_{L}=C_{L_{O}}$ and $C_{g}=0$.

The approximate solution of Equations 11 and 12 can be obtained using the apparent mass transfer coefficient $\left(K_{L} a_{\text {(Apparent })}\right)$ which can be used to describe Equation 11 as follows:

$$
\frac{d C_{L}}{d t}=-K_{L} a_{(\text {Apparent })} C_{L}
$$

Integration of Equation 18 yields the $C_{L}$ concentration time
Table 1. Parameters of the simultaneous differential equations solution

\begin{tabular}{l|l}
\hline$a_{11}=-K_{L} a$ & $r_{1}=\frac{-a_{1}+\sqrt{a_{1}^{2}-4 a_{2}}}{2}$ \\
$a_{12}=\frac{K_{L} a}{\alpha_{N H_{3}} H}$ & $r_{2}=\frac{-a_{1}-\sqrt{a_{1}^{2}-4}}{2}$ \\
$a_{21}=\frac{V_{L} K_{L} a}{V_{g}}$ & $A=\frac{r_{2}-a_{11}}{r_{2}-r_{1}} C_{L_{O}}$ \\
$a_{22}=-\left(\frac{V_{L} K_{L} a}{V_{g} \alpha_{N H_{3}} H}+\frac{Q_{g}}{V_{g}}\right)$ & $B=\frac{a_{11}-r_{1}}{r_{2}-r_{1}} C_{L_{O}}$ \\
$a_{1}=a_{22}-a_{11}$ & \\
$a_{2}=a_{11} a_{22}-a_{12} a_{21}$ &
\end{tabular}

function that best fits the experimental data, as follows:

$$
C_{L}=C_{L_{O}} e^{-K_{L} a_{(\text {Apparent })} t}
$$

Similarly, Equation 12 can be rewritten in the form:

$$
V_{g} \frac{d C_{g}}{d t}=K_{L} a_{(\text {Apparent })} C_{L} V_{L}-Q_{g} C_{g}
$$

Substituting for $C_{L}$ from Equation 19 into Equation 20 then solving the resulting linear differential equation yields:

$$
C_{g}=\frac{\frac{V_{L}}{V_{g}} K_{L} a_{(\text {Apparent })} C_{L_{o}}}{\left(\frac{Q_{g}}{V_{g}}-K_{L} a_{(\text {Apparent })}\right)}\left(e^{-K_{L} a_{(\text {Apparent })} t}-e^{-\frac{Q_{g}}{V_{g}} t}\right)
$$

Equations 16 and 17 provide the exact solution for $C_{L}$ and $C_{g}$ and Equations 19 and 21 provide the approximate solution. In this case, both solutions represented the experimental data very closely, as described in the following section.

\section{Discussion}

The experimental data presented by Yoon et al. ${ }^{1}$ describe the variations of the concentration of total ammonia in solution with time under a variety of temperatures, $\mathrm{pH}$ values, and aeration rates (Table 2). The experimental data can adequately be described by the exact solution of the mass balance equation (Equation 16), or by the simplified solution expressed in Equation 19. For example, Figures 2 to 5 present the experimental data fitted with the model expressed in Equation 16. The fitting of the model to the experimental data was performed using the least square method and the "Solver" tool in the 2003 Microsoft Excel. As expected, the model provided an excellent fit to the experimental data.

The $K_{L} a$ values obtained using the exact solution in Equation 16 were compared to the $K_{L} a_{\text {(Apparent) }}$ values obtained using the simplified solution in Equation 19. The comparison results are shown in Table 2. As expected, the comparison revealed that the values of the mass transfer coefficients obtained using the exact and simplified solutions were relatively close. It should be 
Table 2. Comparison of $K_{L} a$ and $K_{L} a_{\text {(Apparent) }}$ values obtained using the exact and simplified solutions

\begin{tabular}{ccccll}
\hline $\mathrm{pH}$ & $\mathrm{Temp}$ & $Q_{g 2}$ & $Q_{g 1}$ & $K_{L} a$ & $K_{L} a_{\text {(Apparent) }}$ \\
\hline 8.9 & 30 & 2.5 & 10 & 0.0020 & 0.0021 \\
9.9 & 30 & 2.5 & 10 & 0.0040 & 0.0040 \\
10.8 & 30 & 2.5 & 10 & 0.0055 & 0.0055 \\
11.9 & 30 & 2.5 & 10 & 0.0050 & 0.0056 \\
10 & 20 & 2.5 & 10 & 0.002 & 0.0016 \\
10 & 30 & 2.5 & 10 & 0.0040 & 0.0040 \\
10 & 40 & 2.5 & 10 & 0.0066 & 0.0070 \\
10 & 50 & 2.5 & 10 & 0.0088 & 0.0097 \\
10 & 30 & 2.5 & 0 & 0.0008 & 0.0008 \\
10 & 30 & 5 & 0 & 0.0023 & 0.0025 \\
10 & 30 & 10 & 0 & 0.0048 & 0.0044 \\
10 & 30 & 20 & 0 & 0.0081 & 0.0080 \\
10 & 30 & 2.5 & 0 & 0.0008 & 0.0008 \\
10 & 30 & 2.5 & 10 & 0.0039 & 0.0041 \\
10 & 30 & 2.5 & 20 & 0.0047 & 0051 \\
10 & 30 & 2.5 & 30 & 0.0061 & 0.0070 \\
\hline
\end{tabular}

noted that the values obtained for $K_{L} a$ relate to the values of the different model parameters (i.e., $\alpha_{N_{3}}, H, V_{L}, V_{g}, Q_{g}$ ) which are influenced by the $\mathrm{pH}$, temperature, and airflow rate.

The exact and simplified models accounted for variations in the different experimental conditions in an excellent manner. The impact of changing the various experimental conditions
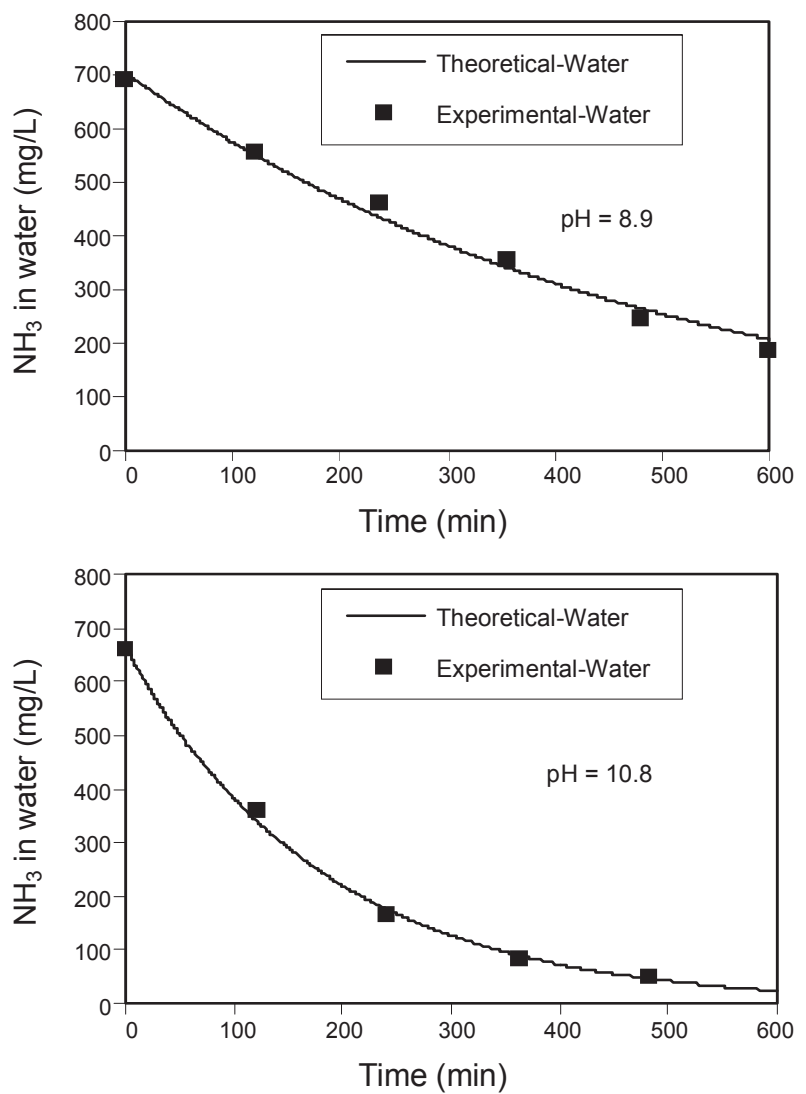

(temperature, $\mathrm{pH}$, and airflow rates) are reflected in the various models parameters, as shown in Table 3.

As an extension of the analysis presented by Yoon et al. ${ }^{1}$, models describing the apparent $\mathrm{pH}$-dependence of the estimated mass transfer coefficients $\left(K_{L} a\right.$ and $\left.K_{L} a_{\text {(Apparent })}\right)$ listed in Table 2 are presented below. Noting that the true ammonia mass transfer coefficient is $\mathrm{pH}$-independent, the apparent dependency of $K_{L} a$ in Equation 16 and $K_{L} a_{\text {(Apparent })}$ in Equation 19 on the $\mathrm{pH}$ can mathematically be described based on the analysis presented by Howe and Lawler ${ }^{4}$ and Shanableh ${ }^{5}$ for gases that undergo acid-base reactions in water. The ammonia mass balance described in Equation 11, $\frac{d C_{L}}{d t}=-K_{L} a\left(C_{L}-C_{L S}\right)$, can be expressed in terms of the concentration of ammonia $\left(C_{\mathrm{NH}_{3}}\right)$, the equilibrium concentration of ammonia $\left(\mathrm{C}_{\mathrm{NH}_{3} \mathrm{~S}}\right)$, and the $\mathrm{pH}-$ independent mass transfer coefficient $\left(K_{L} a_{(p H-\text { Independent })}\right)$ rather than in terms of the total concentration of ammonia $\left(C_{L}\right)$, the total equilibrium concentration of ammonia $\left(C_{L S}\right)$ and the apparently $\mathrm{pH}$-dependent transfer coefficient $\left(K_{L} a\right)$, as follows:

$$
\frac{d C_{L}}{d t}=-K_{L} a_{(p H-\text { Independent })}\left(C_{\mathrm{NH}_{3}}-C_{\mathrm{NH}_{3} \mathrm{~S}} \mathrm{~S}\right.
$$

Noting that $\mathrm{C}_{\mathrm{NH}_{3}}=\alpha_{\mathrm{NH}_{3}} \mathrm{C}_{\mathrm{L}}$ and that $\mathrm{C}_{\mathrm{NH}_{3} \mathrm{~S}}=\alpha_{\mathrm{NH}_{3}} \mathrm{C}_{\mathrm{LS}}$, then Equation 22 can be rewritten as Equations 23 and 24, with Equation 25 resulting from comparing Equation 11, $\frac{d C_{L}}{d t}=-K_{L} a\left(C_{L}-C_{L S}\right)$, with Equation 24.
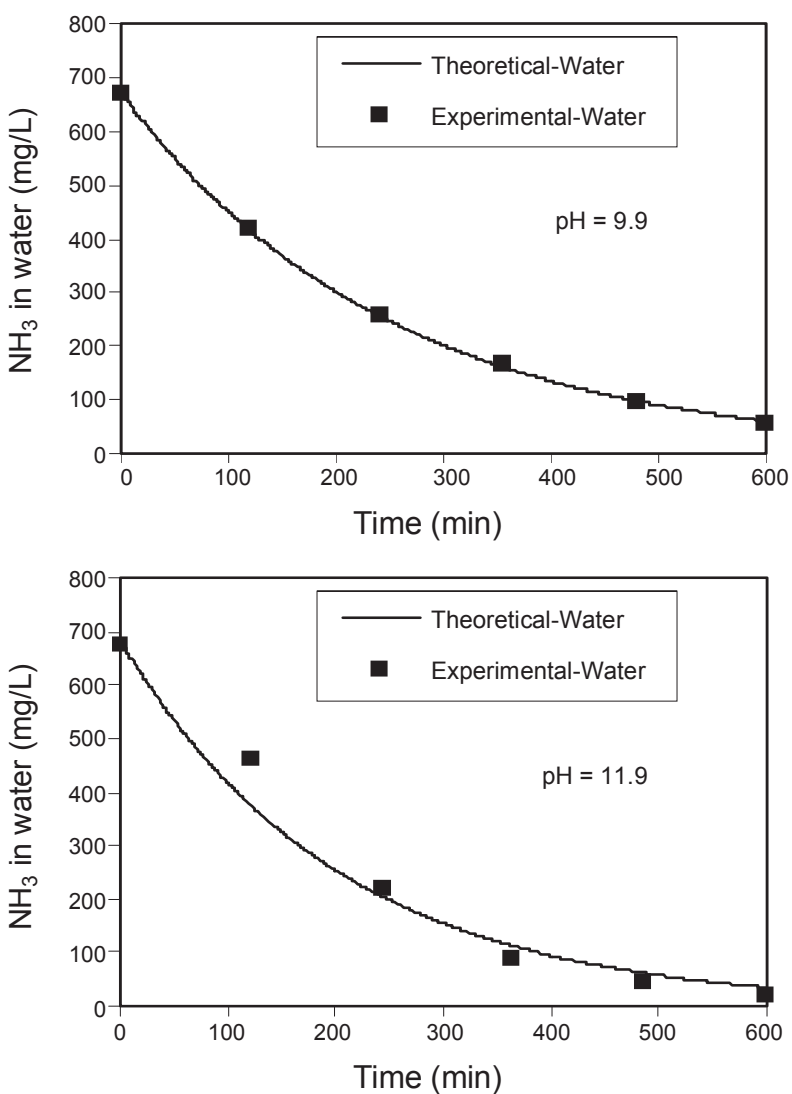

Figure 2. Effect of $\mathrm{pH}$ on ammonia removal $\left(\mathrm{NH}_{3}\right.$ in water refers to $\left.C_{L}\right)$. 



Figure 3. Effect of temperature on ammonia removal $\left(\mathrm{NH}_{3}\right.$ in water refers to $\left.C_{L}\right)$.
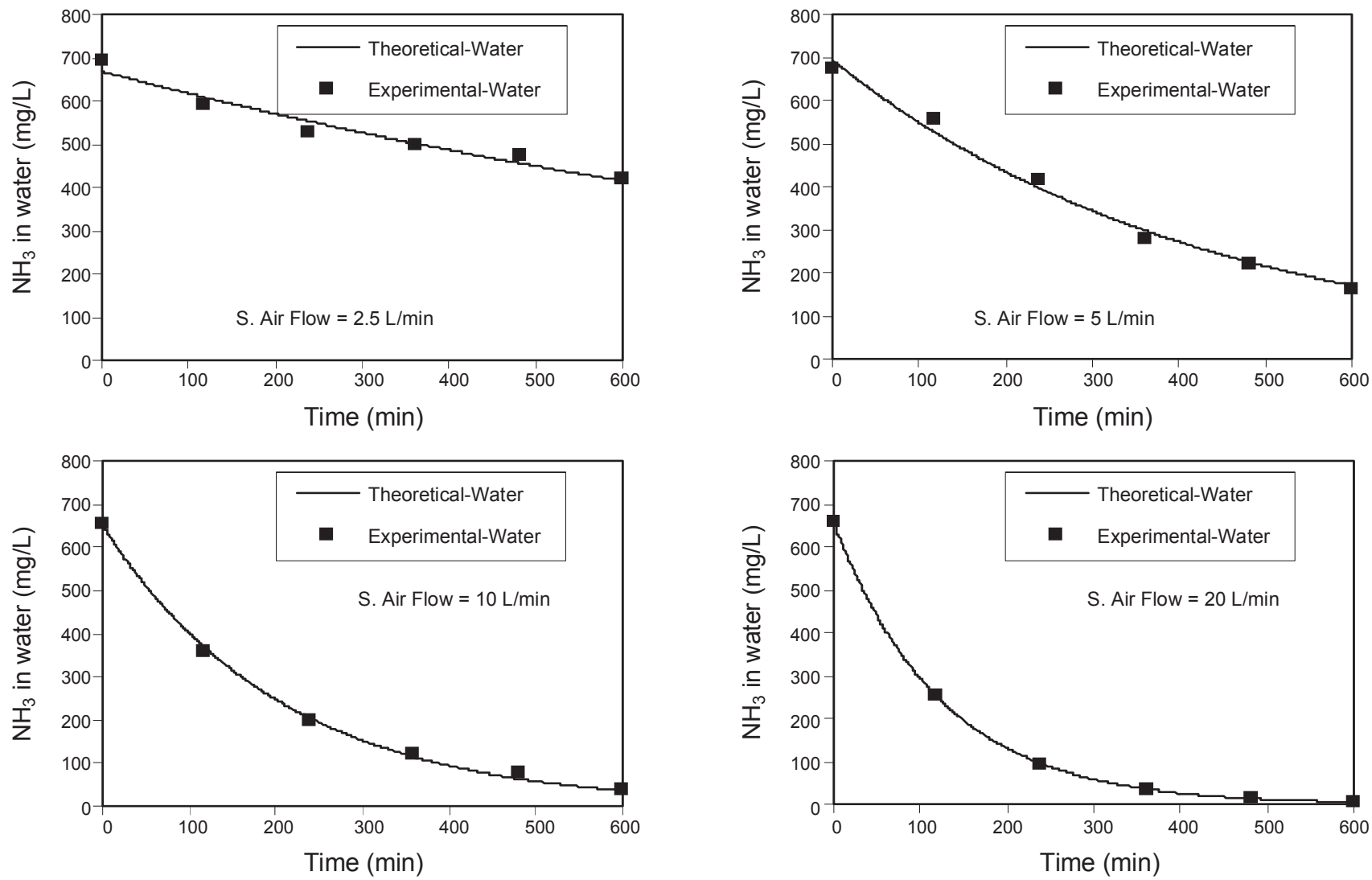

Figure 4. Effect of submerged aeration rate on ammonia removal $\left(\mathrm{NH}_{3}\right.$ in water refers to $\left.C_{L}\right)$. 

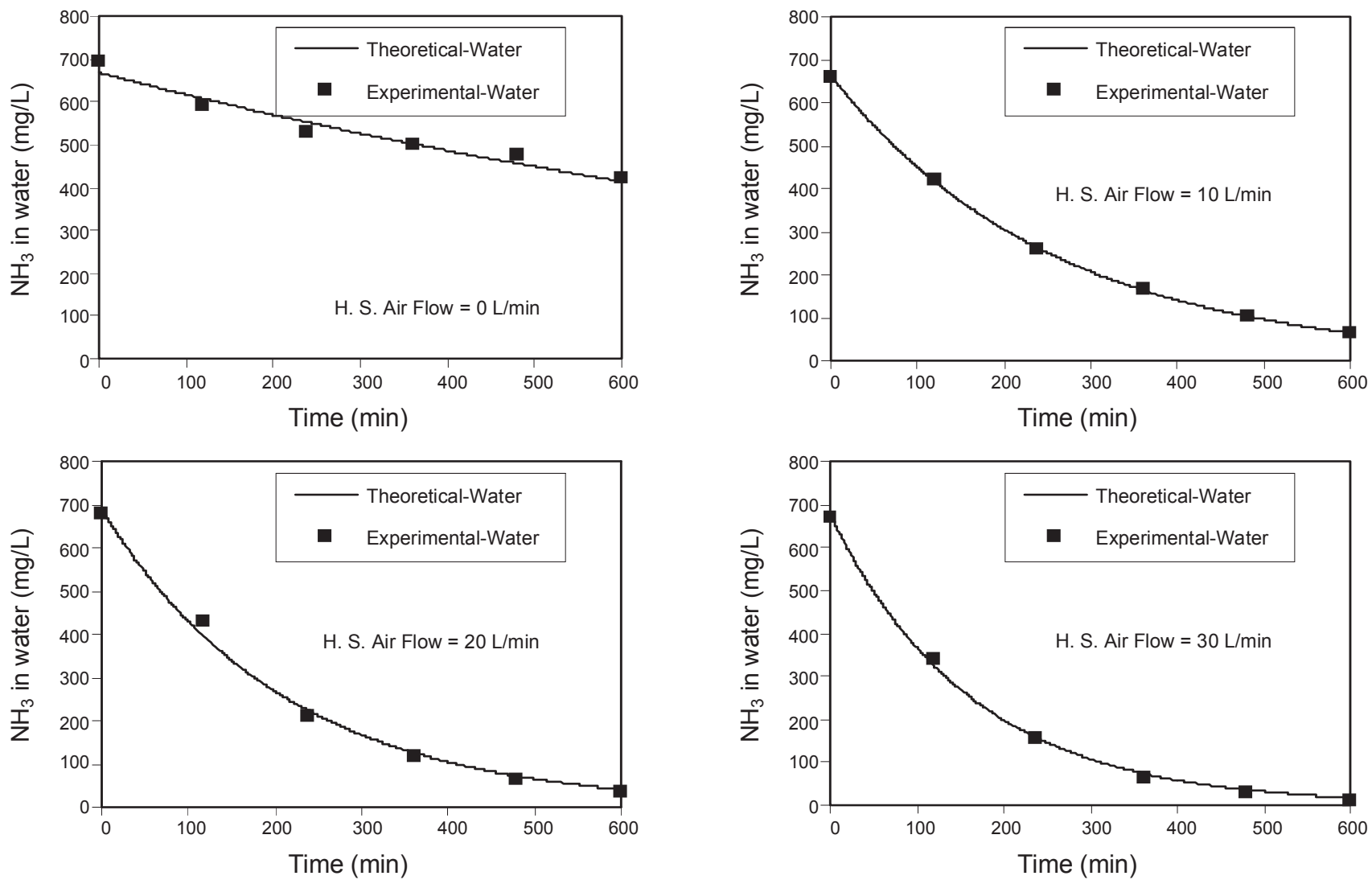

Figure 5. Effect of headspace aeration rate on ammonia removal $\left(\mathrm{NH}_{3}\right.$ in water refers to $\left.C_{L}\right)$.

Table 3. Impact of varying the experimental conditions on the model parameters

\begin{tabular}{|c|c|c|}
\hline Experimental Condition & Affected Parameter & Comments \\
\hline Temperature Change & $K_{L} a, \alpha_{N H_{3}}, H, V_{L}, V_{g}, Q_{g}$ & $\begin{array}{l}\text { The transfer rate, Henry's constant, and Equilibrium constant for the reaction } \\
\mathrm{NH}_{4}^{+}=\mathrm{NH}_{3}+\mathrm{H}^{+} \text {are affected. The volumes and flow rate are also affected. }\end{array}$ \\
\hline $\mathrm{pH}$ & $K_{L} a, \alpha_{N_{3}}$ & $\alpha_{\mathrm{NH}_{3}}$ increases and $K_{L} a$ increases as a result of $\alpha_{\mathrm{NH}_{3}}$ increase (as discussed below) \\
\hline Air Flow Rate Increase & $K_{L} a, Q_{g}$ & $K_{L} a$ depends on bubble size and aeration rate. \\
\hline
\end{tabular}

$$
\begin{aligned}
& \frac{d C_{L}}{d t}=-K_{L} a_{(p H-\text { Independent })}\left(\alpha_{N_{3}} C_{L}-\alpha_{N_{3}} C_{L S}\right) \\
& \frac{d C_{L}}{d t}=-\alpha_{N H_{3}} K_{L} a_{(p H-\text { Independent })}\left(C_{L}-C_{L S}\right) \\
& K_{L} a=\alpha_{N H_{3}} K_{L} a_{(p H-\text { Independent })}
\end{aligned}
$$

Similarly, Equation 18, $\frac{d C_{L}}{d t}=-K_{L} a_{(\text {Apparent })} C_{L}$, can be rewritten in terms of the concentration of ammonia $\left(C_{\mathrm{NH}_{3}}\right)$ rather than the total concentration of ammonia $\left(C_{L}\right)$, as in Equation 26, which leads to Equations 27 and 28.

$$
\frac{d C_{L}}{d t}=-K_{L} a_{(\text {Apparent-pH-Independent })} C_{N H_{3}}
$$

$$
\begin{aligned}
& \frac{d C_{L}}{d t}=-\alpha_{\mathrm{NH}_{3}} K_{L} a_{(\text {Apparent-pH-Independent })} C_{L} \\
& K_{L} a_{(\text {Apparent })}=\alpha_{\mathrm{NH}_{3}} K_{L} a_{(\text {Apparent-pH-Independent })}
\end{aligned}
$$

The data in Figure 6 show the apparent dependence of $K_{L} a$ and $K_{L} a_{\text {(Apparent) }}$ on the $\mathrm{pH}$. Using Equations 25 and 28, the values of the $\mathrm{pH}$-independent constants were estimated to be $K_{L} a_{(p H-\text { Independent })}=0.0051$ per minute and $K_{L} a_{\text {(Apparent- } p H-}$ Independent $)=0.0053$ per minute. Clearly, the relationships assumed by the functions expressed by Equations 25 and 28 in Figure 6 represented the experimentally determined $K_{L} a$ and $K_{L} a_{\text {(Apparent) }}$ values in an excellent manner. It should be noted that Equations 22 to 27 apply if the $\mathrm{pH}$ is assumed to remain constant during the mass transfer process, as was the case in this study. For situations in which the $\mathrm{pH}$ changes as a result of mass 

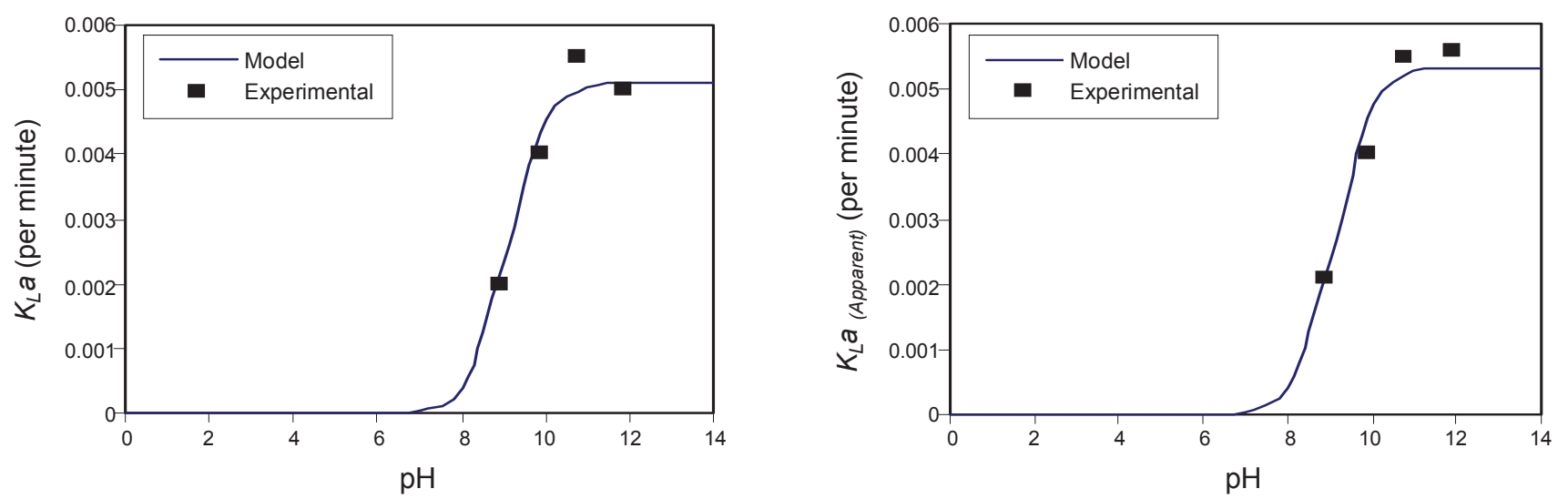

Figure 6. Apparent dependence of the mass transfer coefficients in Table 2 on the $\mathrm{pH}$.

transfer, alternative models are available, as discussed elsewhere ${ }^{5}$ in details.

\section{Conclusions}

In this article, modified mathematical models describing ammonia removal from a batch experimental system and extending the analysis presented by Yoon et al. ${ }^{1}$ were presented. The modified models provide straight foreword solutions to the massbalance differential equations describing ammonia removal by air stripping from the experimental system with gaseous headspace. Two modified models were presented: a model based on an exact solution of the differential equations that describe the system performance; and a simplified solution, both of which represented the experimental data in an excellent manner. The analysis was also extended to mathematically describe the appa- rent $\mathrm{pH}$-dependence of the mass transfer coefficients obtained in the analysis.

Acknowledgments. The authors acknowledge the significant contributions of the authors ${ }^{1}$ of the original work discussed in this article, and the contributions of the referees, whose comments helped improve the quality of the material presented in this article.

\section{References}

1. Yoon, H.; Lim, J.-H.; Chung, H.-K. Bull. Korean Chem. Soc. 2008, 29(3), 555-561.

2. Smith, P. G.; Arab, F. K. 1988, 38, 333-343.

3. Cheung, K. C.; Chu, L. M.; Wong, M. H. 1997, 94, 209-220.

4. Howe, K. J.; Lawler, D. F. Jour. AWWA 1989, 81, 61-66.

5. Shanableh, A. Amer. J. Eng. Appli. Sci. 2(4), 726-734. 